\title{
Economic Advancement of Tourism Industry in Uzbekistan
}

\section{Firdavs Saliev ${ }^{1}$, Mukhammadkhon Soliev ${ }^{2 *}$}

${ }^{1}$ The Founding Member, Chief Executive Officer, FS Capital Investment, London, UNITED KINGDOM

${ }^{2}$ Regional Business Development Director, City Study Group, Samarkand, UZBEKISTAN

*Corresponding Contact:

Email: muhammadsoliyev@hotmail.com

Keyword: Silk Road, Uzbekistan, Tourism Management, Central Asia, Travel facilitation, investment destinations

\section{INTRODUCTION}

The tourism sector is one of the most significant economic activities in most countries worldwide. Its direct economic impact has significant influences on their GDPs. Tourism's total contribution to the global economy rose to $9.5 \%$ of global GDP (US \$7 trillion),not only outpacing the wider economy, but also growing faster than other significant sectors such as financial and business services, transport and manufacturing. In total, nearly 266 million jobs were supported by Travel \& Tourism in 2013 - 1 in 11 of all jobs in the world (Rochelle Turner, 2013).

Since the break-up of the Soviet Union in 1991, the former Soviet Asian States (Kazakhstan, Kyrgyzstan, Tajikistan, Turkmenistan, and Uzbekistan) present considerable opportunities to become a major tourist destination in the way of unique cultural, historical, archeological, and natural attractions. After becoming independent, the policy and model of tourism development in these countries was mainly based on improving tourism infrastructure (Coulibaly et al., 2012). Well-located World Heritage sides of Central Asian States, amusing history of medieval scientists, and undiscovered nature of people make attractive for visitors from all over the world. A vital factor in the history of the southern part of the region was its location astride 
the most direct trade route between China and Europe, the so-called Silk Route which began to be developed in the Roman times (Kemal Kantarci, Muzaffer Uysal, \& Vincent P. Magnini, 2014). Countries like Kazakhstan, Kyrgyzstan, Turkmenistan, Uzbekistan, and Tajikistan contain a marvelous and rich untapped tourism interest that has prodigious potential to organize different type of uncommon accomplishments ("Central Asia: Problems and Perspectives of International Tourism :: SlavomírHorák," 2014).

The direct contribution of Travel \& Tourism to GDP in 2013 was UZS 1,061.9bn ( $0.9 \%$ of GDP). This is forecasted to rise by $5.1 \%$ to UZS 1,116.6bn in 2014.This tension primarily reflects the economic activity generated by industries such as hotels, travel agents, airlines and other passenger transportation services (excluding commuter services). Nevertheless, it also includes, for example, the activities of the restaurant and leisure industries directly supported by tourists. The straight contribution of Travel \& Tourism to GDP is expected to grow by $6.2 \%$ pa to UZS $2,030.0$ bn $(0.9 \%$ of GDP) by 2024 (Figure 1$)$.

Figure 1: Direct contribution of travel and tourism to GDP in Uzbekistan* UZBEKISTAN: DIRECT CONTRIBUTION OF TRAVEL \& TOURISM TO GDP
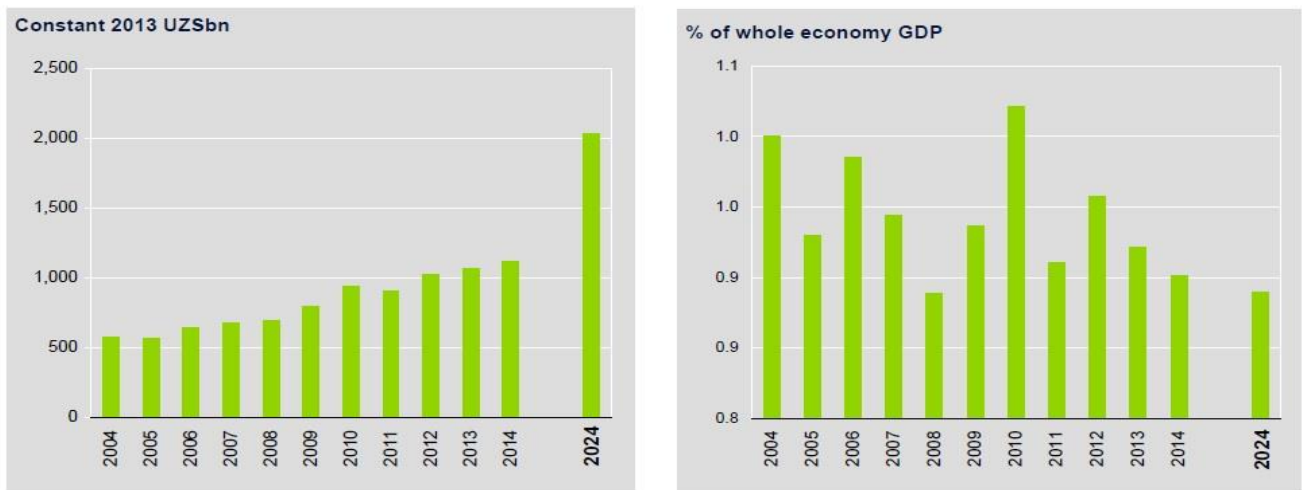

* WTTC Travel and Tourism Economics impact 2014

The government of Uzbekistan pays a vast deal of attention on the development of the tourist industry: the development of services defined as one of the top priorities of socioeconomic development of the country.

Figure 2: International tourism, number of arrivals in Uzbekistan (*)

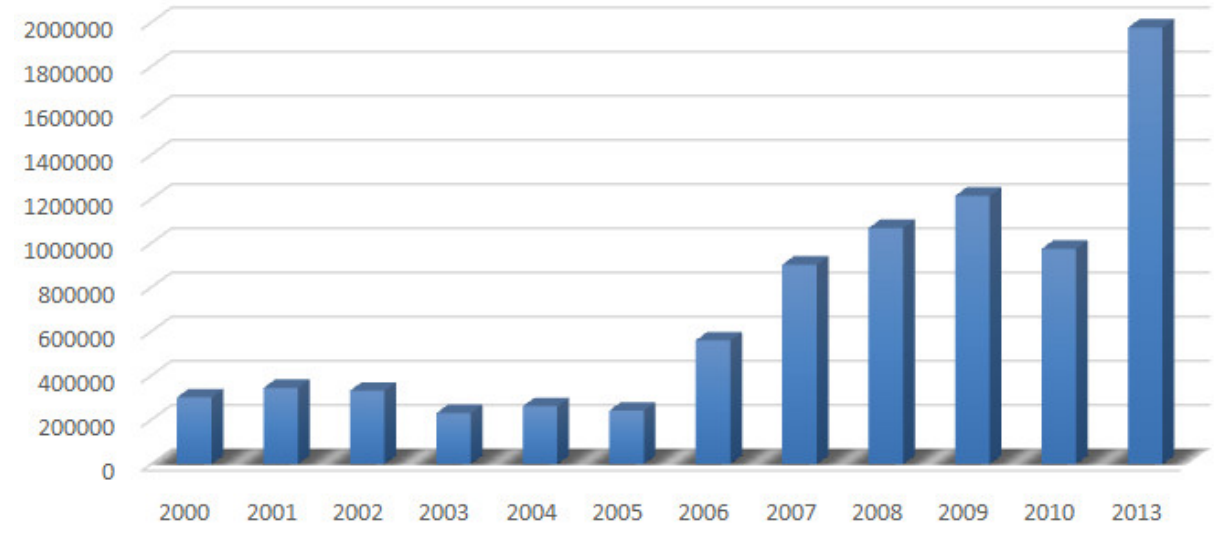

(*)Based on"Uzbektourism" national company and http:/ / databank.worldbank.org 
However in 2010 the number of visitors was 975000, totally international tourism arrival tendency of Uzbekistan illustrates overall upward trend since 2000 up today. Based on tourism "National Company" data, the amount of tourists in Uzbekistan were 1,977,600 in 2013 (Figure 2).

Accounting for this, significant contribution to the advancement of the socio-economic situation brings tourism and its rapidly growing segments to become one of the leading sectors of the world economy, hospitality segment has contributed considerably on economic advancement of Uzbekistan too. The need to travel, to know various cultures, to meet people from other countries, to be in contact with nature, is now ingrained in the culture of our modern society. Tourism is at the same time a driver and a consequence of globalization. As a key economic sector, it is often the foremost source of income for dynamically developing countries as Uzbekistan creating jobs and opportunities particularly for the vulnerable segments of the population (Coulibaly et al., 2012). In the short period, Uzbekistan as one of the major tourism destination of Central Asia has contributed significantly on the deployment of tourism and hospitality. According to World Ranking report, it is underlined in 121 positions absolutely, rated 18 positions with longterm growth out of 184 countries in total (Figure 3).

Figure 3: World ranking statistics (WTTC Travel and Tourism Impact 2014)

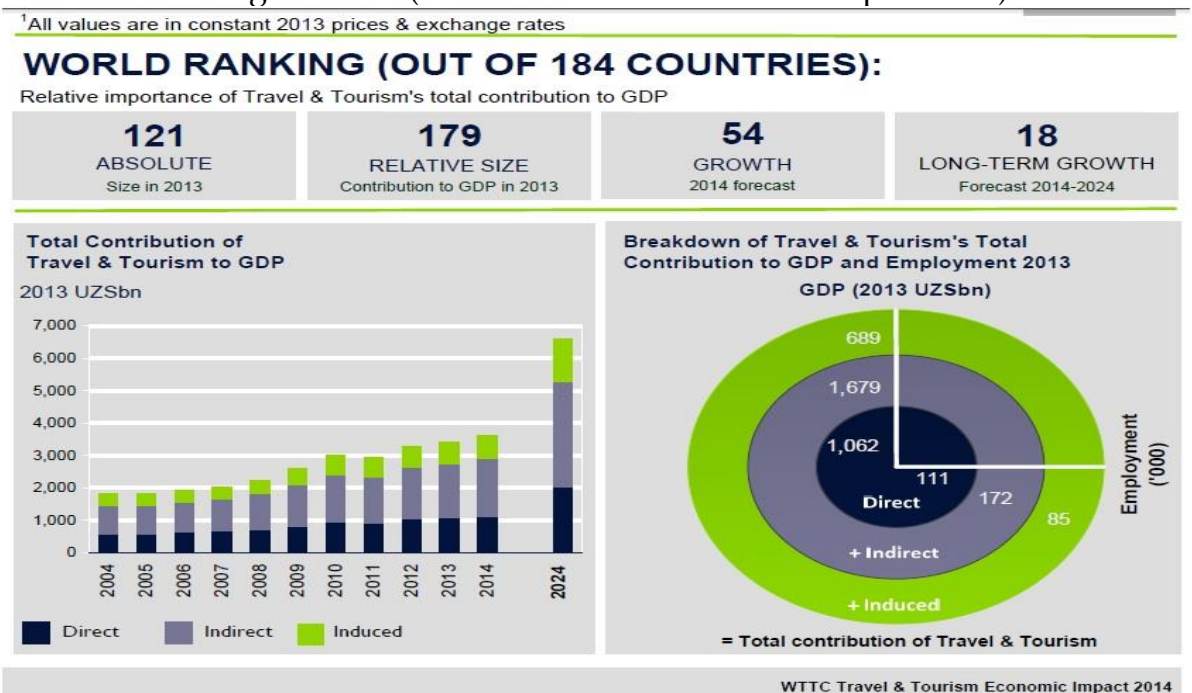

Additional issues include an invitation to local and international stakeholders to invest in Silk Road tourism and the endorsement of country's offer to host a Silk Road Support Office in Samarkand that began operations office of the World Tourism Organization to promote tourism along the Silk Road in 2004 ('Declarations | UNWTO Silk Road Programme', 2014) . Current programs and investigations by The World Tourism Organizations and other World Heritage Institutions like UNESCO, ICOMOS and UCL have been addressing to maintain the quality and shape of the entire destination through some proposals for the edges and routes as a part of the provisional Silk Roads World Heritage. The role of this project has involved unprecedented cooperation among members of the destination. The chief target of the program is dedicated on specific Silk Road Heritage Corridors crossing Central Asian countries like Kazakhstan, Kyrgyzstan, Tajikistan and Uzbekistan as well as China with some offers ('UNWTO Silk Road Programme', 2013). 
Beside this, world-renowned research institution "Euromonitor" that conducts extensive network of strategic analysts in 80 countries around the world and provides the depth of global, national and local business information required in today's increasingly international business environment showed analysis of tourism industry in Uzbekistan in other Central Asian countries as well.

According to the research made by "Euromonitor" and "Uzbektourism", future tendencies of tourist expenditure will probably go up considerably shortly. The below-mentioned figure (Figure 4) discloses the expenditure of tourist is anticipated to rocket up to 2.481.90 annually by the end of the period. The proliferation of this index on the five -year period from 2010-2015 has known one of the main positive indicators of tourism in the country.

Figure 4: Forecast Outgoing Tourist Expenditure: Value 2010-2015, UZS billion (*)

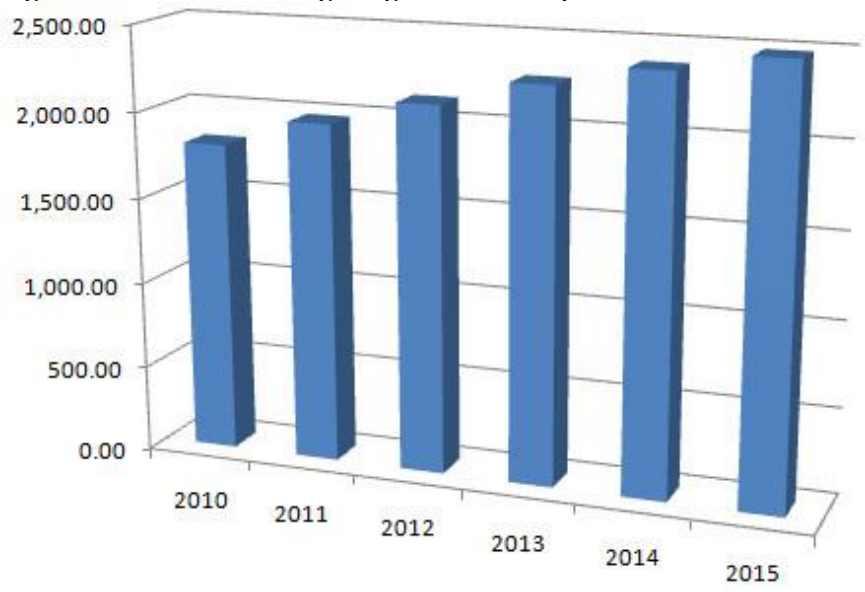

(*) Data based on http:/ / www.euromonitor.com research group

Travel \& Tourism generated 111,000 jobs directly in 2013 (0.8\% of total employment) and this is forecast to grow by $2.4 \%$ in 2014 to 114,000 ( $0.8 \%$ of total employment). This analysis includes employment by hotels, travel agents, airlines and other passenger transportation services (Figure 5).

Figure 5: The direct contribution of Travel and Tourism to Employment. The case of Uzbekistan*

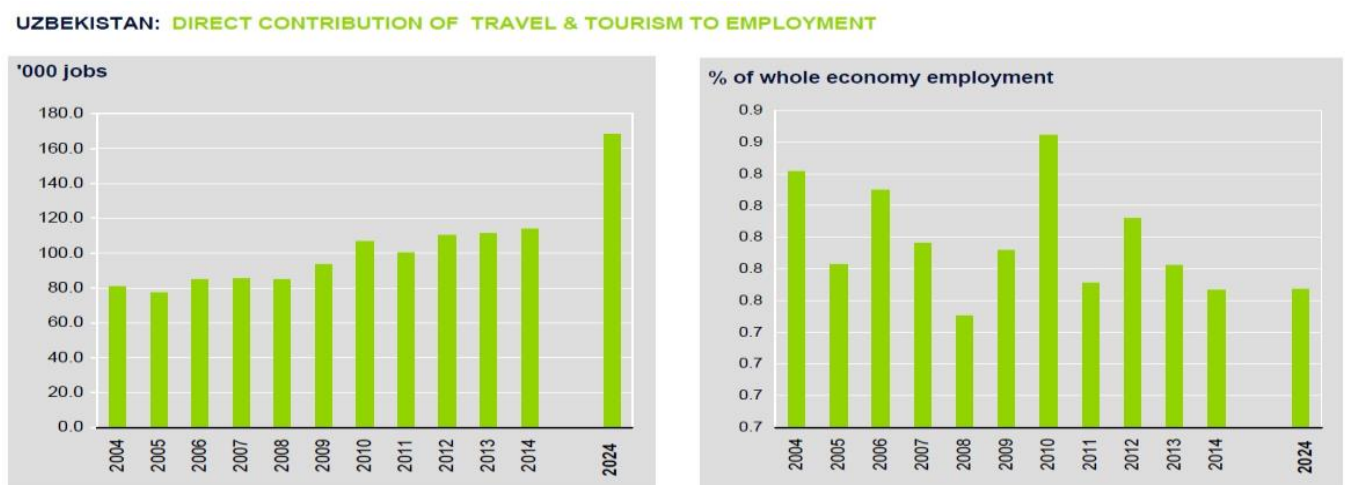

* WTTC Travel and Tourism Economics impact 2014 
It also includes, for example, the activities of the restaurant and leisure industries directly supported by tourists. By 2024, Travel \& Tourism will account for 168,000 jobs directly, an increase of $4.0 \%$ pa over the next ten years.

The total contribution of Travel \& Tourism to employment (including wider effects from investment, the supply chain, and induced income impacts) was 368,000 jobs in 2013 (2.6\% of total employment). This is projected to rise by $2.9 \%$ in 2014 to 379,000 jobs $(2.6 \%$ of total employment).By 2024, Travel \& Tourism is anticipated to support 556,000 jobs (2.5\% of total employment), an increase of $3.9 \%$ pa over the period.

\section{Methodology}

As a core aim this research which chosen the analyzing and diversifying the actual problems of the tourism industry and proposing the ways of further development. On this direction, we monitored the latest statistics based on reports of aforementioned tourism authority of Uzbekistan- "Uzbektourism", research groups WTTC Travel and Tourism economic impact and "Euromonitor" with the prove of authors who had made investigations on Silk Road touristic destination and its role in Central Asian states commercial deployment ('Declarations | UNWTO Silk Road Programme', 2014). As a major Silk Road tourist destination, the country possesses exotic tourist potential, distinct monuments of prehistoric times with unique natural landscapes, which may focal role to become one of the principal tourist states on the globe. That is why much attention devoted in Uzbekistan to the development of tourism and expansion of corresponding infrastructure as one of the priority directions of the nation's socio-economic development (Knobloch, 2013).

Acclaimed as the paramount route in the history of humankind, the ancient Silk Road formed the first connection between the East and the West and was an important vehicle for trade between the ancient empires of China, Central and Western Asia, the Indian peninsula, and Rome. The Silk Road was more than just trade routes; it symbolized the multiple advantages arising from cultural exchange. As a result, countless historical and cultural sites persist along the network of famous paths. There are significant opportunities for destinations along the Silk Road corridors to join efforts for building transnational tourism initiatives to promote and develop shared heritage under the Silk Road brand, particularly for developing states (David Airey \& Myra Shackley, 1997). By taking a collaborative approach to emerging tourism for the Silk Road corridors, it is underlined that:

- $\quad$ sustainable approaches to destination management will be applied across the region

- dispersal of visitation across the region will improve

- the length of stay and yield will increase

- new opportunities for investment will open up

- international relations will be strengthened

- new opportunities for public-private sector partnerships will be realized

- touristic services will be expanded, and flow of tourist will be enlarged

As well as, by 2020 it is predicted that China, Russia, India and the Middle East's trends will increase more than 200 million tourists annually visiting (Handbook on E-marketing for Tourism Destinations, 2008) . Therefore, as one of the main Silk Road tourism destinations, Central Asian countries will be able to attract a vast amount of visitors from all over the world. As Edgar Knobloch (2013) mentioned, countries of Central Asian undoubtedly have abundant resources and potential for development of tourism. However countries need integration and modernization to become competitive in these businesses. 
Additional issues include an invitation to local and international stakeholders to invest in Silk Road tourism and the endorsement of country's offer to host a Silk Road Support Office in Samarkand that began operations office of the World Tourism Organization to promote tourism along the Silk Road in 2004 ("Declarations | UNWTO Silk Road Programme," 2014). More and more, in the country located unique sacred places that are valuable for people professing religions such as Islam, Christianity, and Buddhism. These resources could provide an opportunity for further development of religion tourism sector in the area. (Faranda \&Nolle, 2011; Kantarci, 2007; UNWTO, 2012b) Also, the availability of a large number of natural treasures like mountains, lakes, rivers, meadow woods, deserts and national gardens can help to develop ecologically and adventure tourism in these countries. Furthermore, an increasing number of tour operators include sport, business, and recreational tourism packages to diversify tourism supply (Anthony, Appari, \& Johnson, 2014).

Objectively assessing the situation, it should be noted that the government pays considerable attention to the development of tourism. During the years of independent development in Uzbekistan established a legal framework and tourism infrastructure. Currently operate more than 900 organizations and companies, which have a license for tourist activity (subjects of tourist activity), of which 500 hotels, 371 - travel agencies (tour operators and travel agents), with about $90 \%$ of tourism organizations and companies related to the private sector, that affects the formation of a competitive environment in the tourism system to provide tourist services. Air gateway international airports are operating in Tashkent, Samarkand, Bukhara, Urgench, Nukus and Navaiy.

\section{BACKGROUND OF TOURISM IN UZBEKISTAN}

Uzbekistan in the way of integration with other Central Asian countries, with its richly diverse cultural inheritance and wealth of natural tourism attractions spanning across 12,000 kilometers, unique World Heritage Sites and through distinctive tourism presence, is making a great interest of tourist from all over the world (Kemal Kantarci, Muzaffer Uysal, \& Vincent P. Magnini, 2014). On the other hand, the Silk Road is a unique network of tourism destinations with significant potential for improves, and competence could push up tourism businesses. Commercial interest in the region has grown considerably over recent years, with ancient connections between the Middle East and Central Asia are being revitalized in a surge of investment and trade in energy, infrastructure, and manufacturing. Stronger economies, improved infrastructure and connectivity, advances in information technology and enhanced mobility are creating new opportunities for tourism (Knobloch, 2013).

The 'Silk Road' has been travelled along for centuries by conquerors, traders, missionaries, geographers and, more recently, tourists. It served as a fundamental mode of exchanging cultures, crafts, ideas, technologies, beliefs and peoples. Currently, corridor cities of this trade way, such as Samarkand, Bukhara and Khiva, have been appealing flow of travelers from all over the world. Since 1991, coinciding with the independence of Uzbekistan from the former Soviet Union, there has been a revival of interest in the Silk Road - for cultural exchange, trade and tourism. After having received its independence the state has been established the policy and model of tourism development (Coulibaly et al., 2012).Tourism as one of the largest and fastest growing economic sectors in the world, and has a considerable role to play in delivering sustainable development in many countries. At the same time, it must be well managed so that it benefits local communities and the natural and cultural environments upon which it depends on.

It is believed that tourism, covering employment, decent work and human capital, reflects the fact that tourism is fundamentally a people-based activity. Careful planning of human resources, involving consultation with private enterprises and employee representatives, is 
needed to ensure that tourism can fulfill its employment creation potential and has a sufficient supply of suitably skilled labor to meet future growth in Uzbekistan developing destinations (Samia et al., 2011).

During these years of independence, mentioned government and tourism committees have done successful job at a national and local aspect. It is noticeable that, organizational and structural changes implemented, a new system of state regulation and control was established, preconditions for infrastructure development were created and mechanism of preservation and restoration of cultural and historical attractions were ensured. As the result of infrastructural improvement of tourism facilities and industry modernization, made up new job places and established supply chains. Therefore, working with informal traders and enterprise formation and, more widely, the application and use of tourism charges and collateral benefit from tourism investment that make easy to launch small business and entrepreneurship facilities in tourism area (Allison, 2004). This tension emphasizes the need to ensure that local communities are consulted, engaged and empowered to engage with tourism development and operations that may affect their livelihood and society in whole.

\section{THE WAYS OF TOURISM DEVELOPMENT IN THE COUNTRY}

As one of the dynamically developing States of this region, Uzbek government has done efficacious job and working closely with the Ministry of Economy, Ministry of Foreign Economic Relations, Investments and Trade (MFERIT), Ministry of Finance of the Republic of Uzbekistan to attract foreign investments and grants in tourism businesses, which could be one of the real act of program of strategic advancement. In particular, over the past few years passport prepared 10 investment projects to attract foreign grants for projects in the field of training for the tourism, manufacturing and tourist maps, brochures and other presentation materials and videos, rental movies on foreign TV channels totaling 790 thousand USD (S. Adilxodjayeva \& S. Muratayev, 2014). As part of the deployment of tourism development programs in the regions for 2013 and 2015, pays special attention to attracting foreign investment in the tourism sector. For example, a program of tourism development in the Khorezm region for 2013 and 2015, provided to attract foreign investments and grants equal to U.S. \$ 15.4 million for the restoration of historical and cultural monuments, construction of hotels, restaurants and roadside infrastructure services for tourists, trade and entertainment centers, training, etc. Work on diversification of tourism, the creation of new tours and programs offered by foreign and local tourists: it's climbing, and horse riding tours and walks, camel safaris, jeep safaris, off-road tours, fishing, rafting - rafting, heli-skiing, ecotourism, adventure, educational tours and others.

The growth of tourism in the country is directly related to the issues of training, retraining and advanced training. When it comes to the development of national tourism, special emphasis is laid on international cooperation and the study of advanced international experience. The single National Stand, called “Uzbekistan", represents beginning from 2013, the Republic's tourist potential at various international exhibitions and fairs. And the results of participation in the following large-scale tourist events confirm the correctness of a given strategy: Fitur (Madrid, Spain), Emitt (Istanbul, Turkey), Balttour (Riga, Latvia), ITB (Berlin, Germany), MITT (Moscow, Russia), TopResa (Paris, France), JATA ( Tokyo, Japan), TTG (Rimini, Italy), WTM (London, the UK) and others. The number of cooperation agreements concluded by Uzbekistan in the course of these events is impressive.

The UNWTO highly assessed the leading role played by the Uzbekistan in solidifying international collaboration in the development of tourist infrastructure on the Great Silk Road. Like this, a regional office of this prestigious international organization was opened in 
Uzbekistan as far back as 1994. Nowadays, the UNWTO office in Uzbekistan is successfully for the benefit of international tourism development in the Silk Road nations(Hanks, 2005).

As well as that, this organization is involved in implementing a number of projects. It also maintains active cooperation with national tourist organizations in UNWTO member states. The demonstration on the Euro news Channel of an advertising clip that promotes Uzbekistan's tourist potential, and a series of special documentary films about the country's ancient towns of Samarkand, Shakhrisabz, Bukhara and Khiva, has helped to acquaint millions of its spectators with the rich historical and cultural heritage of Uzbek people. Moreover, in order to promote touristic, cultural and historical potential of Uzbekistan, Ministry of Foreign Affairs, embassies and missions, regularly held events (presentations and briefings), dedicated to the tourism potential of Silk Road crossroad and World Heritage sites of main historical and cultural centers of Uzbekistan.

\section{TOURISM MODERNIZATION}

Globally the challenges that countries are facing in the tourism industry are numerous and complex. However, addressing these challenges require a high level of collaboration and coordination to marshal the resources that possess Uzbekistan.

Speaking about the development of tourism in the country, we should note the importance of tourism deployment model of government and the steps of modernization, systematization of services and integration of tourism infrastructure suppliers in worldwide tourism market, foreign investments and credits in the industry could be underlined as a central. Commercial interest in the region has grown considerably over recent years, with ancient connectors between the Middle East and Asia being revitalized in a surge of investment and trade in energy, infrastructure and manufacturing. According to UNWTO, government need to improve infrastructure and make easy its connectivity, advancement of Information Computer Technologies (ICTs) and enhancement mobility could make more opportunities for tourism industry of country('Handbook on E-marketing for Tourism Destinations - World Tourism Organization', 2013.).

Yet a number of barriers are hindering tourism development in Central Asian countries, including Uzbekistan. Visa and border crossing formalities, transport infrastructure, corporate governance and quality assurance some issues that underlined attention of Silk Road recommendations from global tourism organization ("Strategic Recommendations for enhancing Tourism with a Special Focus on Central Asia," 2012). In addition, experts and specialists of tourism emphasized the importance of modernization and integration of sector and industry due to create better business opportunities and deployment of tourism destination in territory. In order to tackle these issues following proposals on Marketing \& Destination Management, Destination Management \& Investment, Travel Facilitation could be addressed as a main key point for the development of tourism sector in the Central Asian tourism destination.

\section{Destination Management \& Marketing}

The Silk Road is a destination brand which has huge potential for growth. Investigations made by UNTWO researchers demonstrate that the Silk Road motivates more online discussions than any trade networks, accounting for approximately $30 \%$ of international discussions. Yet, very minor part Silk Road destinations are exploiting the marketing and promotional potential of their historic and cultural connections with the travel route. Applying market inquiry and better recognizing travel inspirations and the strength of this brand will allow destinations to be more intensify and develop competitiveness in their strategies of national marketing ("Policy and 
Practice for Global Tourism - World Tourism Organization', 2013). In order to tackle this issue, specialists have listed following concepts as crucial key factors;

- Inaugurate devoted section on the official websites of the Silk Road destination and its partner

- Classify and use unique selling points and hallmarks of own Silk Road of countries

- Involve purchasers and travelers under the same brand name by diffusing ICT as well as crowd sourcing and social media channels

According to historical facts, almost 30 countries was united The Ancient Silk Road and shared their culture, tradition and customs as well as history to one another. The legacy of the Silk Road can be vividly shown at architecture, gastronomy, religion, ideology and technology of these countries (Handbook on E-marketing for Tourism Destinations, 2008). These factors should be used by DMOs and focused on cooperating together pooling resources and executing alliance marketing that celebrate this shared history and motivate travel to the Silk Road.

- Diversify key partners and innovative approaches for joint Silk Road marketing operations

- Integrate and unite resources on market intelligence's gathering

- Collaborate with tour operators, airlines, and other enterprises which engaged with this sector in cross-marketing creativities and product deployment

Enhancement countries' common product offering and stimulate more 'word of mouth' promotion to contribute to a stronger, more globally familiar with Silk Road destination brand would be done by working together and developing new trans-boundary thematic routes and experiences based on the Silk Road destinations (Handbook on E-marketing for Tourism Destinations, 2008).

\section{InVestment Destination \& Management}

As the Silk Road destinations comprise of the complete network of overland and nautical routes, retracing the steps of some most renowned explorers of all times. Yet a general drawback of data available and the compound logistics of travelling these roads prevent many prospective travelers from selecting to visit the Silk Road. Destinations need to pay much more attention on developing tour operators by assimilating audits and diversifying problem areas that recently hinder the connection of Silk Road routes. Private sector players of international and national scale should be engaged in the long-term vision of the destinations' competitiveness and sustainability aspects. Commitment and investment from local small executives will help guarantee the involvement of the local community.

Undoubtedly, investments in sustainable infrastructure are paramount for the long-term perspective and survival of the Silk Road. Following measures could make better performance of above-mentioned factors in country:

- Advancement of road system

- enhanced air connectivity via regular flight to main cities in globe

- inauguration of low-cost airlines for domestic or Central Asian tourism business

- By the way of railway enhancement develop of high speed trains among major Silk Road destinations of Central Asia

- Creating tourism office centers online visitor and destination

- Improve amount of investments created by foreigners and governmental bodies

- Make accessible internet by Wi-Fi availability in major sightseeing sides

In order to help guarantee a 'bottom-up' method to destination management, establishments should empower local societies and stakeholders by providing relevant training and volume building across all phases of destination management, principally in regional areas. 
Developed skills and services in the tourism sector are obligatory to ensure review while transparency in business is main feature to building strong business relations and attracting direct foreign investment

- Improvement of diffusing of Information and Communication Technologies

- Language skills among service specialist

- Applying of management systems world-renowned hotel networks

- Well-organized governance and transparency in international business

- Enrich natural and heritage resources by establishing sustainable management

\section{Further Suggestions Toward Enhancement of TOURISt Sphere}

Firstly it is absolutely pivotal, in order to further improve the procedure for licensing and giving permission for tourism activities, forming extra conditions for entrepreneurship and small businesses, experts from UNWTO proved and verified program to the of the Republic of Uzbekistan which provides:

- Classification and the conception of different kinds of tourist activity through simplifying the licensing requirements for family businesses in terms of forming the statutory fund to provide industrial services.

- Facilitating the licensing acquirements for shareholders that provide services to domestic tourism, in terms of forming the legislative fund to provide various types of services.

- Permitting individuals the right to obtain a license for the provision of services as a tour guide.

- National company delegated to admire regulations on the issuance of qualified certificates to employees of tourist organizations, guides and the rules of certification of tourist services, as well as rules for the provision of tourism services.

Secondly, to intensify the various types of tourism, increasing the duration of the tourist season of the country according to legislative act "About Amendments to the Rules of stay of foreign citizens and stateless persons in the Republic of Uzbekistan", providing a list of addition persons released from temporary registration, foreign tourists on guided tours and/or instructor-conductor in the tour, or part thereof, organized by the tourist organization outside of urban areas, if the term of this tour or part thereof does not exceed 10 days. At the same time, these tours are organized after giving the authorized state body in the sphere of tourism of the list of tourists with their passport data, the route of showing the locations of stops, as well as other documents endorsing the adoption of the legislation of measures to ensure the defense of tourists.

Further and even more importantly, to obtain optimization the taxation of small businesses in the service sector, including tourism, attributed the company with the utmost number of employees up to 25 units, which promotes the use of a simplified procedure for taxation of accommodations with a small amount of room number.

\section{TRAVEL FACILITATION}

In order to simplify visa procedures for tourists, government and responsible officials should make optimize process of issuance as well as make some reforms of legislature system in terms of visa periods, apply online access to visa applications. As one of the Silk Road's main merits is that it is as a marvelous network of destinations, multiple barriers to the smooth cross-border movement of tourists recently make it virtually impossible for travelers to undertake multi-destination tourism. Information provided by authorities on visa processes needs to be accurate and simple to acquire, available online and up-to-date.

- Improve the system of visa provision on arrival and electronic visa accessibility 
- $\quad$ Standardization of single, double and ,multiple entry visas

- Optimization of visa periods to 30,60,90 days

- Enlarge more nationalities not requiring letters of invitation

By the way border crossing advancement procedures and services for tourists' state should modify the potential for economic incentive and environmental enhancement by taking an inventive approach to cross-border rules.

Proposals for further improvement of services for tourists:

Upgrading level of the English speaking staff at the borders; tourist information; shopping; money exchange; transit accommodation; guided service through buffer zones (for guides, drivers with badges); regular working hours signage; food and beverage services; restrooms and first aid facilities.

Suggested innovative methods to cross border administration:

- Mutual tourism development plans;

- unique and marvellous package tour services;

- local handicraft markets

- integrate e-tourism frameworks

- cross-border job exchange and mobility

- cultural and traditional events;

- $\quad$ worldwide multidisciplinary joint programs

To sum up, Uzbekistan as a major partner of Silk Road tourist destination program could tackle various issues with the support of some international and non-governmental organizations. Consequently, some drawbacks of tourism industry will be prevented and some privileges could be provided for small businesses and entrepreneurship.

\section{CONCLUSION}

As tourism stimulates infrastructure development of the country, has a strong multiplication effect and helps diversify the economy, supports local culture and crafts and environmental protection, it is very actual for the Republic of Uzbekistan with its transitional economy, moreover it is important as Uzbekistan is a country with vast capabilities in tourism. The travel and tourism industry is a leading export industry in worldwide, Central Asian counties could contribute considerable as well.

Moreover, with vast underused capabilities in tourism and diversity of tourist attractions represent the potential of tourism in these tourism destinations. Location of the area, corridors on the Great Silk Road, with cities, which were core points of the trade, make destination attractive one for the flow of tourists globally. Accessibility of various tourism types, distinct traditions and unique cultural background of Central Asia has considered as one of the main key factor tourism and hospitality businesses. After have been establishing and implying global experience, the attractiveness of tourism estimated to become as one of the crucial one in the Central Asian destination. Furthermore, the optimization of visa facilities has listed as one of the essential advancement of tourism policy by the UNWTO research group.

As one of the chief Silk Road tourism destination, Central Asian states have great potential to advance sector of hospitality and tourism that create a range amount of promotions for different spheres. In the other perspective, tourism sector in Central Asia has already established and its policy has led to some fundamentals improvements in the last 20 years. Further investigations and explorations may be addressed to identify obstacles of the industry by learning all its sub-sectors. In briefly, Central Asian states, such as Kazakhstan, Kyrgyzstan, Turkmenistan, Tajikistan, and Uzbekistan have great potential of tourism deployment as the whole. Established policies and conducted measurements in countries 
have made already its results. Upcoming diversifications and modernizations in the industry may contribute exponentially on the economies of the Central Asian countries.

\section{REFERENCE}

Anthony, D. L., Appari, A., \& Johnson, M. E. (2014). Policy brief. Journal of Health and Social Behavior, $55(1), 107$.

Bhatia, A. K. (2006). The Business of Tourism: Concepts and Strategies. Sterling Publishers Pvt. Ltd.

Central Asia: Problems and Perspectives of International Tourism : Slavomír Horák. (2014). Retrieved April 24, 2014, from http://www.slavomirhorak.net/news/central-asia-problems-and-perspectives-ofinternational-tourism/

Coulibaly, S., Deichmann, U., Dillinger, W. R., Ionescu-Heroiu, M., Kessides, I. N., Kunaka, C., \&Saslavsky, D. (2012). Eurasian Cities: New Realities along the Silk Road. World Bank Publications.

Declarations|UNWTO Silk Road Programme. (2014). Retrieved April 25, 2014, from http://silkroad.unwto.org/en/content/declarations

Faranda, R., \&Nolle, D. B. (2011). Boundaries of ethnic identity in Central Asia: titular and Russian perceptions of ethnic commonalities in Kazakhstan and Kyrgyzstan. Ethnic and Racial Studies.

Fifth International Meeting on the Silk Road. (2014). Retrieved April 25, 2014, from http://silkroad.unwto.org/en/event/fifth-international-meeting-silk-road-samarkand-republic-uzbekistan

Food Industry - WorldFood Uzbekistan. (2014). Retrieved April 26, 2014, from http://www.iteuzbekistan.uz/vis/worldfood/eng/index.php

Go, F. M., \& Jenkins, C. L. (1997). Tourism and economic development in Asia and Australasia. Pinter Pub Ltd.

Handbook on E-marketing for Tourism Destinations. (2008). World Tourism Organization.

Kantarci, K. (2007). Perceptions of foreign investors on the tourism market in central Asia including Kyrgyzstan, Kazakhstan, Uzbekistan, Turkmenistan. Tourism Management, 28(3), 820-829.

Kemal Kantarci, MuzafferUysal, \& Vincent P. Magnini. (2014). Tourism in Central Asia Cultural Potential and Challenges. Retrieved April 24, from http:/ / www.appleacademicpress.com/title.php?id=9781771880558

Knobloch, E. (2013). Treasures of the Great Silk Road. The History Press.

National Company "UzbekTourism." (2014). Retrieved April 25, 2014, from http://www.uzbektourism.uz/index.php/ru/

Policy and Practice for Global Tourism - World Tourism Organization. (n.d.). Retrieved May 15, 2014, from http://www.e-unwto.org/content/jj25vv/?p=bb96d121a1c1474a95d64048aff500db\&pi=0

Qu, H., Kim, L. H., \&Im, H. H. (2011). A model of destination branding: Integrating the concepts of the branding and destination image. Tourism Management, 32(3), 465-476.

Strategic Recommendations for enhancing Tourism with a Special Focus on Central Asia.pdf. (2012). $\begin{array}{llll}\text { Retrieved May 15, 2014, from } & \text { 15, }\end{array}$ http://dtxtq4w60xqpw.cloudfront.net/sites/all/files/pdf/recommendations_tour_operators_forum_20 12_electronic_0.pdf

The World Factbook. (2014). Retrieved April 25, 2014, from https://www.cia.gov/library/publications/theworld-factbook/geos/uz.html

The World of Leisure - 2014. (2014). Retrieved April 26, 2014, from http:/ / www.tourfair.uz/en/mutv-vistavka

UNWTO Annual Report 2013. (2014). Retrieved April 24, 2014, from http://www2.unwto.org/publication/unwto-annual-report-2013

UNWTO Silk Road Programme. (2013). Retrieved April 25, 2014, from http://silkroad.unwto.org/ publication/developing-sustainable-tourism-strategy-silk-roads-heritage-corridors

UNWTO. (2012a). Global Report on Food Tourism.pdf. Retrieved April 24, 2014, from http://dtxtq4w60xqpw.cloudfront.net/sites/all/files/pdf/food_tourism_ok.pdf

UNWTO. (2012b). UNWTO Tourism Highlights 2012 Edition. Retrieved January (p. 16). UNWTO.

UzReport.uz. (2014). Retrieved May 4, 2014, from http:/ /economics.uzreport.uz/news_e_118225.html

Xu, G. (2013). Tourism and Local Development in China: Case Studies of Guilin, Suzhou and Beidaihe. Routledge.

Yearbook of Tourism Statistics. (2014). World Tourism Organization Pubns. 